\title{
Cardiac (valve) surgery in the elderly—who decides you are too old?
}

\author{
Gloria Faerber, MD, and Torsten Doenst, MD, PhD
}

\footnotetext{
From the Department of Cardiothoracic Surgery, Jena University Hospital, Friedrich-Schiller-University of Jena, Jena, Germany.

Disclosures: Authors have nothing to disclose with regard to commercial support.

Received for publication Nov 27, 2017; accepted for publication Dec 4, 2017; available ahead of print Jan 23, 2018.

Address for reprints: Torsten Doenst, MD, PhD, Department of Cardiothoracic Surgery, Friedrich-Schiller-University of Jena, Am Klinikum 1, 07747 Jena, Germany (E-mail: doenst@med.uni-jena.de).

J Thorac Cardiovasc Surg 2018;155:1461-2

$0022-5223 / \$ 36.00$

Copyright (c) 2017 by The American Association for Thoracic Surgery

https://doi.org/10.1016/j.jtcvs.2017.12.025
}

\section{In my mind, I can still run and jump that fence!}

-Quotation from an 85-year-old patient

with mitral regurgitation and severe heart failure

Discussions about age as a risk factor for cardiac surgery are not new. ${ }^{2}$ However, they are currently experiencing a renaissance for 2 reasons. First, society ages as life expectancy increases. ${ }^{3}$ Second, new interventional techniques for the treatment of structural heart disease are rapidly developing. ${ }^{4}$ Thus, the statement: "this patient is too old for surgery" is more frequently heard, with the subtle suggestion that interventional techniques may be associated with lower periprocedural mortality. ${ }^{5}$

In the literature on patients at advanced age, all outcomes have been described for both surgery and intervention (ie, superior, neutral, and inferior mortality ${ }^{6-9}$ ). Considering the aforementioned quote, the question arises whether mortality is the optimal endpoint for this patient population. Certainly, one needs a survivor to get a long-term follow-up, but it appears questionable whether mortality is the best parameter for decision-making in patients in whom preoperative age is already above average life expectancy. ${ }^{3}$

In this issue of the Journal, Chivasso and colleagues ${ }^{1}$ demonstrate in their analysis of 247 patients with degenerative mitral regurgitation and significant fractions of additional valve and coronary pathologies that almost one half of them are still alive at 10 years (specifically if repair was possible). Thus, a good fraction of these patients, who have been described as high risk, ${ }^{1}$ live well into their 90s. This is outstanding, considering an average US life expectancy just less than 80 years. $^{3}$ Others have previously published similar numbers, ${ }^{2}$ and evidence suggests that cardiac surgery (eg, mitral valve repair or bypass surgery) extends the life of elderly patients. ${ }^{7,10}$ We can inform patients even at that age that they will statistically live longer with surgery. However, would this information be the most important driver for our aforementioned

\section{References}

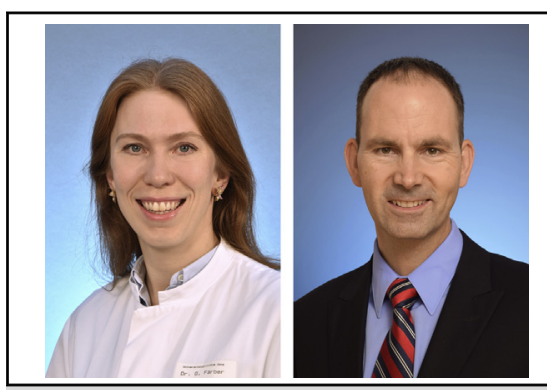

Gloria Faerber, MD, and Torsten Doenst, MD, PhD

Central Message

Octogenarians may seem too old for surgery. Chivasso and colleagues ${ }^{1}$ show good survival for mitral repair $>80$ years. However, at above-average life expectancy preoperatively, quality of life moves to center stage.

See Article page 1474 .

85-year-old patient, or may improvement or stabilization of his quality of life be more important? ${ }^{8}$ What would urge him to take on presumably high perioperative risks?

Chivasso and colleagues ${ }^{1}$ do not address quality of life in their patient population, and risk assessment may not relate to age. ${ }^{8}$ One can only infer from other data that a noncomplicated perioperative course, independent of age, is usually associated with good prognosis and quality of life. ${ }^{7}$ However, we currently know too little about the impact of surgery in elderly patients on quality of life or risk assessment to address this question properly ${ }^{6}$ or to perform a proper comparison with interventional techniques. Future studies on surgical outcome in elderly patients therefore need to contain more information about perioperative risks and impact on symptoms and quality of life for both surgical and interventional techniques.

In this context, we recently demonstrated that patients with preoperative liver dysfunction undergoing cardiac surgery for endocarditis may have perioperative mortality rates of up to $80 \% .^{11}$ Importantly, the $20 \%$ who survived had similar 5-year survival compared with controls and equal quality of life. So, who decides that a patient is too old and/or risky for cardiac surgery?

1. Chivasso P, Bruno V, Farid S, Giorgio P, Modi MA, Benedetto U, et al. Predictors of survival in octogenarians after mitral valve surgery for degenerative disease: 
the Mitral Surgery in Octogenarians (MiSO) study. J Thorac Cardiovasc Surg. 2018;155:1474-82.e2.

2. Nloga J, Hénaine R, Vergnat M, Wautot F, Desebbe O, Robin J, et al. Mitral valve surgery in octogenarians: should we fight for repair? A survival and quality-of-life assessment. Eur J Cardiothorac Surg. 2011;39:875-80.

3. Wikipedia. List of countries by life expectancy. Available at https://en.wikipedia.org/ wiki/List_of_countries_by_life_expectancy. Accessed November 24, 2017.

4. Maisano F, Alfieri O, Banai S, Buchbinder M, Colombo A, Falk V, et al. The future of transcatheter mitral valve interventions: competitive or complementary role of repair vs. replacement? Eur Heart J. 2015;36:1651-9.

5. Andalib A, Mamane S, Schiller I, Zakem A, Mylotte D, Martucci G, et al. A systematic review and meta-analysis of surgical outcomes following mitral valve surgery in octogenarians: implications for transcatheter mitral valve interventions. EuroIntervention. 2014;9:1225-34.

6. Abah U, Dunne M, Cook A, Hoole S, Brayne C, Vale L, et al. Does quality of life improve in octogenarians following cardiac surgery? A systematic review. BMJ Open. 2015;5:e06904.
7. Mark DB, Knight JD, Velazquez EJ, Wasilewski J, Howlett JG, Smith PK, et al. Quality-of-life outcomes with coronary artery bypass graft surgery in ischemic left ventricular dysfunction: a randomized trial. Ann Intern Med. 2014;161: 392-9.

8. O'Neill DE, Knudtson ML, Kieser TM, Graham MM. Considerations in cardiac revascularization for the elderly patient: age isn't everything. Can J Cardiol. 2016;32:1132-9.

9. Pulignano G, Gulizia MM, Baldasseroni S, Bedogni F, Cioffi G, Indolfi C, et al. ANMCO/SIC/SICI-GISE/SICCH Consensus document: Risk stratification in elderly patients undergoing cardiac surgery and transcatheter aortic valve implantation [in Italian]. G Ital Cardiol (Rome). 2016;17:756-89.

10. Khera S, Panza JA. Surgical revascularization in older adults with ischemic cardiomyopathy. Heart Fail Clin. 2017;13:571-80.

11. Diab M, Sponholz C, von Loeffelholz C, Scheffel P, Bauer M, Kortgen A, et al. Impact of perioperative liver dysfunction on in-hospital mortality and long-term survival in infective endocarditis patients. Infection. 2017;45: 857-66. 